\title{
H63D CG genotype of HFE is associated with increased risk of sporadic amyotrophic lateral sclerosis in a single population
}

Qing-Qing Zhang ${ }^{1,2}$, Hong Jiang ${ }^{1,3}$, Chun-Yan Li ${ }^{1,3}$, Ya-Ling Liu ${ }^{1,3}$ and Xin-Ying Tian ${ }^{1,3, *}$

\author{
${ }^{1}$ Department of Neurology, The Second Hospital of Hebei Medical University, West Heping Road 215, Shijiazhuang, Hebei, \\ 050000, P. R. China \\ ${ }^{2}$ Department of Neurology, Binzhou Medical University Hospital, Binzhou, Shandong, 256603, P. R. China \\ ${ }^{3}$ Key Laboratory of Neurology of Hebei Province, Shijiazhuang, Hebei, 050000, P. R. China \\ *Correspondence: txydoc@163.com (Xin-Ying Tian)
}

DOI: $10.31083 /$ i.jin.2020.03.131

This is an open access article under the CC BY-NC 4.0 license (https://creativecommons.org/licenses/by-nc/4.0/).

This paper describes the genetic etiology of sporadic amyotrophic lateral sclerosis in a single population. Polymerase chain reaction-restriction fragment length polymorphism and DNA sample sequencing of 3 common HFE gene variants (C282Y and H63D and S65C) were performed on 10 randomly selected samples of H63D gene variant (124 patients with sporadic amyotrophic lateral sclerosis) and 10 wild types of H63D samples (210 controls). The $\mathrm{C} 282 \mathrm{Y}$ and $\mathrm{S} 65 \mathrm{C}$ gene variant were absent. There were 24 cases $(7.18 \%)$ with H63D heterozygous variants, including 16 cases $(13 \%)$ in the sporadic amyotrophic lateral sclerosis group and 8 cases $(4 \%)$ in the healthy control group. The polymorphism frequency of the H63D gene variant in the sporadic amyotrophic lateral sclerosis group was significantly different than that in the control group $(P<0.05)$, and the difference at allele level, which is still more significant $(P<0.05)$. H63D gene variant could be a risk factor for sporadic amyotrophic lateral sclerosis in a single population. The results showed HFE gene variants play a role in the occurrence of sporadic amyotrophic lateral sclerosis, but its effect should be carefully estimated.

\section{Keywords}

Neurogenetics; amyotrophic lateral sclerosis; motor neuron disease; HFE gene; polymorphism

\section{Introduction}

Amyotrophic lateral sclerosis (ALS) is an idiopathic and fatal neurodegenerative disease of the human motor system. Like other neurodegenerative diseases, about $10 \%$ of ALS is classified as familial diseases, while the remaining $90 \%$ are considered sporadic because they appear to occur randomly throughout the community (Rowland and Shneider, 2001). Further study on the genetic etiology of ALS provides basic insights into the cellular mechanism of neuronal degeneration, and also contributes to the design and testing of disease modeling and targeted therapy. Therefore, it is not surprising that a large number of resources have been used to search for pathogenic variants. Sporadic ALS is suspected to be associated with genetic susceptibility to environmental risk factors (Talbott et al., 2016).

SOD1 is the first gene found to cause ALS (Rosen, 1993). With the rapid development of technology, gene discovery has been dramatically accelerated. Some new ALS genes have also been found, including TARDBP (Sreedharan et al., 2008), profilin 1 (PFN1) gene (Wu et al., 2012), C9ORF72 (Renton et al., 2011), valosincontaining protein (VCP) gene (Johnson et al., 2010), UBQLN2 (Deng et al., 2011), and other genes.

The existence of the SOD1 variant leads to the theory of the role of oxidative stress in the pathogenesis of the disease. One of the leading causes of oxidative stress is the disorder of cellular iron homeostasis. Improper cell iron management and oxidative stress are associated with many neurodegenerative diseases. One of the mechanisms by which cells cannot regulate iron status properly is through variants in the HFE gene (Pietrangelo , 2004). It was found that H63D variant cells had the phenotype of promoting glutamate toxicity (Mitchell et al., 2011), which was one of the causes of ALS. The p. His 63 Asp polymorphism of the HFE gene (c.187C > G, rs 1799945) was found to accelerate the disease progression of SOD1 transgenic mouse (Nandar et al., 2014). The H63D variant in the HFE gene has been found to increase the risk of SALS in several populations (Eum et al., 2015; He et al., 2011; Sutedja et al., 2007), but the conclusion was inconsistent (Chiò et al., 2015; Li et al., 2014; Praline et al., 2012).

In this paper, we determine the relationship between the $\mathrm{C} 282 \mathrm{Y}$ (p.Cys 282 Tyr, A at rs1800562 instead of G), H63D (p. His 63 Asp, G at rs1799945 instead of C), and S65C (p.Ser65Cys, $\mathrm{T}$ at $\mathrm{i} 3002468$ instead of $\mathrm{A}$ ) variants in HFE gene (chromosome $6 \mathrm{p} 21.3$ )and the risk of sporadic ALS (SALS) in a single population. 
Table 1. The basic information on genotyping assays of $\mathrm{HFE}$

\begin{tabular}{|c|c|c|c|c|c|c|c|}
\hline \multirow{3}{*}{ polymorp } & \multirow{3}{*}{ primer } & \multirow{3}{*}{ restriction enzyme } & \multirow{3}{*}{ PCR products } & \multirow{3}{*}{ base change } & \multicolumn{3}{|c|}{ digestion product } \\
\hline & & & & & \multicolumn{3}{|c|}{ mutations } \\
\hline & & & & & wild & homozygous & heterozygous \\
\hline \multirow[t]{4}{*}{$\mathrm{C} 282 \mathrm{Y}$} & 5'-TGGCAAGGGTAAACAGATCC-3' (forword) & Rsa I & $387 \mathrm{bp}$ & $\mathrm{G} \rightarrow \mathrm{A}$ & $247 \mathrm{bp}$ & $247 \mathrm{bp}$ & $247 \mathrm{bp}$ \\
\hline & & & & & $140 \mathrm{bp}$ & $111 \mathrm{bp}$ & $140 \mathrm{bp}$ \\
\hline & 5'-CTCAGGCACTCCTCTCAACC-3' (reverse) & & & & & $29 \mathrm{bp}$ & $111 \mathrm{bp}$ \\
\hline & & & & & & & 29 bp \\
\hline \multirow[t]{3}{*}{$\mathrm{S} 65 \mathrm{C}$} & 5'-ACATGGTTAAGGCCTGTTGC-3' (forword) & Hinf I & $208 \mathrm{bp}$ & $\mathrm{A} \rightarrow \mathrm{T}$ & $147 \mathrm{bp}$ & $208 \mathrm{bp}$ & $208 \mathrm{bp}$ \\
\hline & & & & & $61 \mathrm{bp}$ & & $147 \mathrm{bp}$ \\
\hline & 5'-GCCACATCTGGCTTGAAATT-3'(reverse) & & & & & & $61 \mathrm{bp}$ \\
\hline \multirow[t]{3}{*}{ H63D } & 5'-ACATGGTTAAGGCCTGTTGC-3' (forword) & Mbo I & 208 bp & $\mathrm{C} \rightarrow \mathrm{G}$ & $138 \mathrm{bp}$ & $208 \mathrm{bp}$ & $208 \mathrm{bp}$ \\
\hline & 5'-GCCACATCTGGCTTGAAATT-3' (reverse) & & & & $70 \mathrm{bp}$ & & $138 \mathrm{bp}$ \\
\hline & & & & & & & $70 \mathrm{bp}$ \\
\hline
\end{tabular}

Table 2. Demographic characteristic of the study populations

\begin{tabular}{lccc}
\hline Variable & Patients $\mathrm{n}=124$ & Controls $\mathrm{n}=210$ & $P$-Value \\
\hline Male, $\mathrm{n}$ & 69 & 133 & $0.165^{a}$ \\
Female, $\mathrm{n}$ & 55 & 77 & \\
Mean age (SD), $\mathrm{y}$ & $50.00(10.09)$ & $45.02(10.64)$ & $0.66^{b}$ \\
Spinal onset, $\mathrm{n}$ & 103 & & \\
Bulibar onset, $\mathrm{n}$ & 21 & & \\
Symptom duration $36 \mathrm{~m}$ & 98 & & \\
Symptom duration $>36 \mathrm{~m}$ & 26 & & \\
Age at disease onset $\leq 45 \mathrm{y}$ & 48 & \\
Age at disease onset $>45 \mathrm{y}$ & 76 & \\
\hline
\end{tabular}

Note a: $P$-value for Chi-square test; b: $P$-value for $t$-test.

\section{Materials and methods}

\subsection{Patients population}

One hundred twenty-four patients (69 males and 55 females) with SALS were recruited from the Second Hospital of Hebei Medical University, the Peking University Third Hospital, the West China Hospital, Sichuan University, and the Third Hospital of Hebei Medical University. Patients met the El Escorial criteria for definite, probable, or possible ALS (de et al., 2008). Two hundred ten healthy people matched by age, gender, and nationality were included as the control group. All patients and controls were of Han ethnicity. The ethics committee approved the research plan of the second hospital of Hebei Medical University. All individuals gave written informed consent.

\subsection{Genotyping}

Venous blood $(5 \mathrm{ml})$ was collected from patients and healthy subjects, anticoagulated with sodium citrate, and stored in a refrigerator at $4{ }^{\circ} \mathrm{C}$. DNA was extracted according to the instructions of the blood genomic DNA extraction kit within 1 week after blood collection. The DNA of the final product was stored in a refrigerator at $-80{ }^{\circ} \mathrm{C}$ before use. The genotypes of $\mathrm{C} 282 \mathrm{Y}, \mathrm{S} 65 \mathrm{C}$, and $\mathrm{H} 63 \mathrm{D}$, were analyzed by polymerase chain reaction-restriction fragment length polymorphism (PCR-RFLP), and the necessary information of $H F E$ polymorphism genotyping was shown in Ta- ble 1. 10 samples of H63D variant and 10 wild type H63D samples were randomly selected for PCR amplification and DNA sequencing.

\subsection{Statistical analysis}

SPSS 21 version software was used for statistical processing. $\chi^{2}$ test was used to analyze the frequency distribution of genotypes between the healthy control group and the SALS group. HardyWeinberg equilibrium analysis was performed. $T$-test was used for the age difference between the SALS group and the healthy control group, and the $\chi^{2}$ test was used for gender difference. The odds ratio (OR) and the $95 \%$ confidence interval $(\mathrm{CI})$ of the relative risk were calculated by the unconditional logistic regression method.

\section{Results}

The baseline characteristic was shown in Table 2. There was no statistical difference in age and gender between the control group and the patient group $(P>0.05)$, so a further comparison can be made. The frequency of the H63D allele was in Hardy-Weinberg equilibrium in the patient and control group, respectively $(P>$ 0.05 ) (Table 3). There were 24 cases (7.18\%) with H63D heterozygous variants, including 16 cases $(13 \%)$ in the SALS group and 8 cases $(4 \%)$ in the healthy control group.

The polymorphism frequency of the H63D variant in the SALS group was significantly different from that in the control group $(P$ $<0.05)$. The frequency of CG genotype $(\mathrm{c} .187 \mathrm{C}>\mathrm{G})$ in the SALS group was significantly higher than that in the control group $(P<0.05)$, and the difference at allele level, which was still more significant $(P<0.05)$ (Table 4$)$. Non-conditional logistic regression test showed that the heterozygous variant (CG genotype) of H63D was independently associated with an increased risk of developing SALS (odds ratio 3.74, 95\% CI 1.55-9.02, $P=0.003$ ). The frequencies of C282Y (GG GA AA) and S65C (AA AT TT) sites of $H F E$ gene in the ALS group and healthy control group were $100 \%, 0 \%, 0 \%$ and $100 \%, 0 \%, 0 \%$, respectively, indicating that $\mathrm{C} 282 \mathrm{Y}$ and $\mathrm{S} 65 \mathrm{C}$ variants were absent in our study. The RFLP results of negative samples showed that there was no $\mathrm{C} \rightarrow \mathrm{G}$ variant. The results of positive samples showed that there was a $\mathrm{C} \rightarrow \mathrm{G}$ variant, which was heterozygous. 
Table 3. Chi-square tests for the Hardy-Weinberg equilibrium in SALS patients and controls

\begin{tabular}{cccc}
\hline Gene & Genotype/Allele & Patients (n) $\mathrm{n}=124$ & Controls $(\mathrm{n}) \mathrm{n}=210$ \\
\hline \multirow{2}{*}{ HFE H63D } & Wild type (CC) & 108 & 202 \\
& Heterozygous (CG) & 16 & 8 \\
& Homozygous (GG) & 0 & 0 \\
& $P$ Value & 0.597 & 1.00 \\
\hline
\end{tabular}

Table 4. Gene variant and allele distribution of H63D in patients and controls

\begin{tabular}{ccccc}
\hline Gene & Gene variant/Allele & Patients, $\mathrm{n}=124$ No $(\%)$ & Controls, $\mathrm{n}=210$ No $(\%)$ & $P$ Value* \\
\hline \multirow{2}{*}{ HFE H63D } & Wild type (CC) & $108(87.10)$ & $202(96.19)$ & $0.002^{a}$ \\
& Heterozygous (CG) & $16(12.90)$ & $8(3.81)$ & \\
& Homozygous (GG) & $0(0.00)$ & $0(0.00)$ & 0.003 \\
& C & $232(93.55)$ & $412(98.10)$ & \\
G & $16(7.45)$ & $8(1.90)$ &
\end{tabular}

Note *: $P$-Value for Chi-square test; a: $P$-Value for the CC genotype relative to CG genotype of H63D.

\section{Discussion}

We found that the H63D variant was associated with SALS, which is consistent with previous studies (Wang et al., 2004). Our results are consistent with findings in different populations (Eum et al., 2015; He et al., 2011; Sutedja et al., 2007). Compared with the finding of He et al. (2011), we used different amplification primers and different fragment lengths. We used the course of the disease as the stratification factor for statistical analysis. The patient group in this study had different data sources, and the conclusion was complementary to He et al. (2011), which further expands the population data. The results of Li et al. (2014) and Van Rheenen et al. (2013) showed the opposite conclusions and confirmed that the H63D variant was not associated with ALS risk. The difference in the genetic background in ethnicity of the population could explain the difference of experimental results.

SALS was reported to be associated with the H63D variant in Dutch (Eum et al., 2015), and the H63D variant was associated with a higher age of onset. The mean age of onset in Chinese ALS patients was 49.8 to 54.3 years old in hospital-based studies (Chen et al., 2015; Liu et al., 2014, 2019, 2018; Rosenbohm et al., 2018; Wei et al., 2015), indicating that the onset age of ALS patients in China is earlier than that in other countries. The average age of the experimental subjects was $50.00 \pm 10.09$ years, which was consistent with the other studies. It has been suggested that the age of onset was younger in less developed regions with shorter life expectancy. Older and more severe patients were less likely to be referred to as regional or national referral centers, which partially explained the younger age of onset recorded. Another potential contributing factor was the higher level of environmental pollution in less developed areas (Liu et al., 2018).

The H63D variant in the HFE gene is associated with iron homeostasis disorder and oxidative stress and plays a vital role in the pathogenesis of ALS. Although the relationship between the HFE gene and ALS is still controversial, there is strong evidence in animal experiments. In animal models, the presence of H67D variant of the HFE gene (homologous to H63D in humans) disrupts iron homeostasis in the brain. It is associated with increased oxidative stress in the brain (Nandar et al., 2013) and severe disruption of cholesterol metabolism (Ali-Rahmani et al., 2014). Changes in iron homeostasis and increased oxidative stress were also observed at the cellular level (Lee et al., 2007), and increase glutamate release (Mitchell et al., 2011) and endoplasmic reticulum pressure (Liu et al., 2011). Each of the above mechanisms is considered to be the promoter of ALS pathogenesis (Rothstein, 2009). Therefore, the data suggests that H63D-HFE is a genetic modifier of ALS risk.

Nandar et al. (2014) established a double transgenic mouse line carrying the H67D variant of the HFE gene (homologous with human H63D) and SOD1 (G93A) variant. They found that the H67D variant of the HFE gene can double the survival time and course of disease of transgenic mice. The underlying mechanism is that the H63D variant of the HFE gene changes the pathophysiology of ALS through oxidative stress, gliosis, and cell dysfunction (Nandar et al., 2014). The C282Y variant, rather than the H63D variant, has a more significant impact on serum iron concentration and liver deposition (Adams et al., 2005). In the present work, C282Y and $\mathrm{S} 65 \mathrm{C}$ variants were not present in both patients and controls. The frequency of the CG genotype in the SALS group was significantly higher than that in the control group, and the difference was still significant at the allele level. However, the sample size of this study is too small for subsample analysis. More samples are needed for future research.

\section{Conclusions}

The results suggest that the H63D variant plays a role in the development of SALS. Still, we need to be cautious in extrapolating different geographical regions, as further independent $H F E$ variant association studies are needed.

\section{Ethics approval and consent to participate}

The ethics committee approved the research plan of the second hospital of Hebei Medical University. All individuals gave written informed consent. 


\section{Acknowledgments}

The authors thank the patients and clinicians at The Second Hospital of Hebei Medical University, Peking University Third Hospital, West China Hospital, Sichuan University, and The Third Hospital of Hebei Medical University, who helped to collect and organize data. This study was supported by the Hebei Province Medical Science Research Key Project (08079).

\section{Conflict of Interest}

The authors promise that there is no conflict of interest in this study.

Submitted: May 04, 2020

Revised: August 27, 2020

Accepted: September 02, 2020

Published: September 30, 2020

\section{References}

Adams, P. C., Reboussin, D. M., Barton, J. C., McLaren, C. E., Eckfeldt, J. H., McLaren, G. D., Dawkins, F. W., Acton, R. T., Harris, E. L., Gordeuk, V. R., Leiendecker-Foster, C., Speechley, M., Snively, B. M., Holup, J. L., Thomson, E. and Sholinsky, P. (2005) Hemochromatosis and iron-overload screening in a racially diverse population. New England Journal of Medicine 352, 1769-1778.

Ali-Rahmani, F., Grigson, P. S., Lee, S., Neely, E., Connor, J. R. and Schengrund, C. (2014) H63D mutation in hemochromatosis alters cholesterol metabolism and induces memory impairment. Neurobiology of Aging 35, 1511.

Chen, L., Zhang, B., Chen, R., Tang, L., Liu, R., Yang, Y., Yang, Y., Liu, X., Ye, S., Zhan, S. and Fan, D. (2015) Natural history and clinical features of sporadic amyotrophic lateral sclerosis in China. Journal of Neurology, Neurosurgery and Psychiatry 86, 1075-1081.

Chiò, A., Mora, G., Sabatelli, M., Caponnetto, C., Lunetta, C., Traynor, B. J., Johnson, J. O., Nalls, M. A., Calvo, A., Moglia, C., Borghero, G., Monsurrò, M. R., La Bella, V., Volanti, P., Simone, I., Salvi, F., Logullo, F. O., Nilo, R., Giannini, F., Mandrioli, J., Tanel, R., Murru, M. R., Mandich, P., Zollino, M., Conforti, F. L., Penco, S. and ITALSGEN consortium. (2015) HFE p.H63D polymorphism does not influence ALS phenotype and survival. Neurobiology of Aging 36, 2906.e72906.11.

de Carvalho, M., Dengler, R., Eisen, A., England, J. D., Kaji, R., Kimura, J., Mills, K., Mitsumoto, H., Nodera, H., Shefner, J. and Swash, M. (2008) Electrodiagnostic criteria for diagnosis of ALS. Clinical Neurophysiology 119, 497-503.

Deng, H., Chen, W., Hong, S., Boycott, K. M., Gorrie, G. H., Siddique, N., Yang, Y., Fecto, F., Shi, Y., Zhai, H., Jiang, H., Hirano, M., Rampersaud, E., Jansen, G. H., Donkervoort, S., Bigio, E. H., Brooks, B. R., Ajroud, K., Sufit, R. L., Haines, J. L., Mugnaini, E., Pericak-Vance, M. A. and Siddique, T. (2011) Mutations in UBQLN2 cause dominant $\mathrm{X}$-linked juvenile and adult-onset ALS and ALS/dementia. Nature 477, 211-215.

Eum, K., Seals, R. M., Taylor, K. M., Grespin, M., Umbach, D. M., Hu, H., Sandler, D. P., Kamel, F. and Weisskopf, M. G. (2015) Modification of the association between lead exposure and amyotrophic lateral sclerosis by iron and oxidative stress related gene polymorphisms. Amyotrophic Lateral Sclerosis and Frontotemporal Degeneration 16, 72-79.

He, X., Lu, X., Hu, J., Xi, J., Zhou, D., Shang, H., Liu, L., Zhou, H., Yan, B., Yu, L., Hu, F., Liu, Z., He, L., Yao, X. and Xu, Y. (2011) H63D polymorphism in the hemochromatosis gene is associated with sporadic amyotrophic lateral sclerosis in China. European Journal of Neurology 18, 359-361.

Johnson, J. O., Mandrioli, J., Benatar, M., Abramzon, Y., Van Deerlin, V. M., Trojanowski, J. Q., Gibbs, J. R., Brunetti, M., Gronka, S., Wuu, J., Ding, J., McCluskey, L., Martinez-Lage, M., Falcone, D., Hernandez, D. G., Arepalli, S., Chong, S., Schymick, J. C., Rothstein, J., Landi,
F., Wang, Y. D., Calvo, A., Mora, G., Sabatelli, M., Monsurrò, M. R., Battistini, S., Salvi, F., Spataro, R., Sola, P., Borghero, G., Consortium, I., Galassi, G., Scholz, S. W., Taylor, J. P., Restagno, G., Chiò, A. and Traynor, B. J. (2010) Exome sequencing reveals VCP mutations as a cause of familial ALS. Neuron 68, 857-864.

Lee, S. Y., Patton, S. M., Henderson, R. J. and Connor, J. R. (2007) Consequences of expressing mutants of the hemochromatosis gene (HFE) into a human neuronal cell line lacking endogenous HFE. FASEB Journal 21, 564-576.

Li, M., Wang, L., Wang, W., Qi, X. L. and Tang, Z. Y. (2014) Mutations in the HFE gene and sporadic amyotrophic lateral sclerosis risk: a meta-analysis of observational studies. Brazilian Journal of Medical and Biological Research 47, 215-222.

Liu, M. S., Cui, L. Y., Fan, D. S. and Chinese ALS Association (2014) Age at onset of amyotrophic lateral sclerosis in China. Acta Neurologica Scandinavica 129, 163-167.

Liu, T., Shen, D., Yang, X., Cui, B., Tai, H., Wang, Z., Liu, S., Zhang, K., Liu, M. and Cui, L. (2019) Early onset but long survival and other prognostic factors in Chinese sporadic amyotrophic lateral sclerosis. Journal of Clinical Neuroscience 69, 74-80.

Liu, X., He, J., Gao, F., Gitler, A. D. and Fan, D. (2018) The epidemiology and genetics of Amyotrophic lateral sclerosis in China. Brain Research 1693, 121-126.

Liu, Y., Lee, S. Y., Neely, E., Nandar, W., Moyo, M., Simmons, Z. and Connor, J. R. (2011) Mutant HFE H63D protein is associated with prolonged endoplasmic reticulum stress and increased neuronal vulnerability. Journal of Biological Chemistry 286, 13161-13170.

Mitchell, R. M., Lee, S. Y., Simmons, Z. and Connor, J. R. (2011) HFE polymorphisms affect cellular glutamate regulation. Neurobiology of Aging 32, 1114-1123.

Nandar, W., Neely, E. B., Simmons, Z. and Connor, J. R. (2014) H63D HFE genotype accelerates disease progression in animal models of amyotrophic lateral sclerosis. Biochimica et Biophysica Acta (BBA) Molecular Basis of Disease 1842, 2413-2426.

Nandar, W., Neely, E. B., Unger, E. and Connor, J. R. (2013) A mutation in the HFE gene is associated with altered brain iron profiles and increased oxidative stress in mice. Biochimica et Biophysica Acta (BBA) - Molecular Basis of Disease 1832, 729-741.

Pietrangelo, A. (2004). Hereditary hemochromatosis-a new look at an old disease. The New England Journal of Medicine 350, 2383-2397.

Praline, J., Blasco, H., Vourc'h, P., Rat, V., Gendrot, C., Camu, W. and Andres, C. R. (2012) Study of the HFE gene common polymorphisms in French patients with sporadic amyotrophic lateral sclerosis. Journal of the Neurological Sciences 317, 58-61.

Renton, A. E., Majounie, E., Waite, A., Simón-Sánchez, J., Rollinson, S., Gibbs, J. R., Schymick, J. C., Laaksovirta, H., van Swieten, J. C., Myllykangas, L., Kalimo, H., Paetau, A., Abramzon, Y., Remes, A. M., Kaganovich, A., Scholz, S. W., Duckworth, J., Ding, J., Harmer, D. W., Hernandez, D. G., Johnson, J. O., Mok, K., Ryten, M., Trabzuni, D., Guerreiro, R. J., Orrell, R. W., Neal, J., Murray, A., Pearson, J., Jansen, I. E., Sondervan, D., Seelaar, H., Blake, D., Young, K., Halliwell, N., Callister, J. B., Toulson, G., Richardson, A., Gerhard, A., Snowden, J., Mann, D., Neary, D., Nalls, M. A., Peuralinna, T., Jansson, L., Isoviita, V. M., Kaivorinne, A. L., Hölttä-Vuori, M., Ikonen, E., Sulkava, R., Benatar, M., Wuu, J., Chiò, A., Restagno, G., Borghero, G., Sabatelli, M., Heckerman, D., Rogaeva, E., Zinman, L., Rothstein, J. D., Sendtner, M., Drepper, C., Eichler, E. E., Alkan, C., Abdullaev, Z., Pack, S. D., Dutra, A., Pak, E., Hardy, J., Singleton, A., Williams, N. M., Heutink, P., Pickering-Brown, S., Morris, H. R., Tienari, P. J. and Traynor, B. J. (2011) A hexanucleotide repeat expansion in C9ORF72 is the cause of chromosome 9p21-linked ALS-FTD. Neuron 72, 257-268.

Rosen, D. (1993) Mutations in $\mathrm{Cu} / \mathrm{Zn}$ superoxide dismutase gene are associated with familial amyotrophic lateral sclerosis. Nature 364, 362-362.

Rosenbohm, A., Liu, M., Nagel, G., Peter, R. S., Cui, B., Li, X., Kassubek, J., Rothenbacher, D., Lulé, D., Cui, L. and Ludolph, A. C. (2018) Phenotypic differences of amyotrophic lateral sclerosis (ALS) in China and Germany. Journal of Neurology 265, 774-782. 
Rothstein, J. D. (2009) Current hypotheses for the underlying biology of amyotrophic lateral sclerosis. Annals of Neurology 65, S3-S9.

Rowland, L. P. and Shneider, N. A. (2001) Amyotrophic lateral sclerosis. The New England Journal of Medicine 344, 1688-1700.

Sreedharan, J., Blair, I. P., Tripathi, V. B., Hu, X., Vance, C., Rogelj, B., Ackerley, S., Durnall, J. C., Williams, K. L., Buratti, E., Baralle, F., de Belleroche, J., Mitchell, J. D., Leigh, P. N., Al-Chalabi, A., Miller, C. C., Nicholson, G. and Shaw, C. E. (2008) TDP-43 mutations in familial and sporadic amyotrophic lateral sclerosis. Science 319, 1668-1672.

Sutedja, N. A., Sinke, R. J., Van Vught, P. W. J., Van der Linden, M. W., Wokke, J. H. J., Van Duijn, C. M., Njajou, O. T., Van der Schouw, Y. T., Veldink, J. H. and Van den Berg, L. H. (2007) The association Between H63D mutations in HFE and amyotrophic lateral sclerosis in a dutch population. Archives of Neurology 64, 63.

Talbott, E. O., Malek, A. M. and Lacomis, D. (2016) The epidemiology of amyotrophic lateral sclerosis. Handbook of Clinical Neurology 138, 225-238.

Van Rheenen, W., Diekstra, F. P., van Doormaal, P. T. C., Seelen, M., Kenna, K., McLaughlin, R., Shatunov, A., Czell, D., van Es, M. A., van
Vught, P. W. J., van Damme, P., Smith, B. N., Waibel, S., Schelhaas, H. J., van der Kooi, A. J., de Visser, M., Weber, M., Robberecht, W., Hardiman, O., Shaw, P. J., Shaw, C. E., Morrison, K. E., Al-Chalabi, A., Andersen, P. M., Ludolph, A. C., Veldink, J. H. and van den Berg, L. H. (2013) H63D polymorphism in HFE is not associated with amyotrophic lateral sclerosis. Neurobiology of Aging 34, 1517.

Wu, C., Fallini, C., Ticozzi, N., Keagle, P. J., Sapp, P. C., Piotrowska K., Lowe, P., Koppers, M., McKenna-Yasek, D., Baron, D. M. et al. (2012) Mutations in the profilin 1 gene cause familial amyotrophic lateral sclerosis. Nature 488, 499-503.

Wang, X., Lee, S., Simmons, Z., Boyer, P., Scott, K., Liu, W. and Connor, J. (2004) Increased incidence of the Hfe mutation in amyotrophic lateral sclerosis and related cellular consequences. Journal of the Neurological Sciences 227, 27-33.

Wei, Q., Chen, X., Zheng, Z., Guo, X., Huang, R., Cao, B., Zeng, Y. and Shang, H. (2015) The predictors of survival in Chinese amyotrophic lateral sclerosis patients. Amyotrophic Lateral Sclerosis and Frontotemporal Degeneration 16, 237-244. 